\title{
ОСОБЕННОСТИ ИЗМЕНЕНИЯ НЕЙРОН-СПЕЦИФИЧЕСКОЙ ЕНОЛАЗЫ В СЫВОРОТКЕ КРОВИ ПРИ БОЛЕЗНИ ПАРКИНСОНА В ЗАВИСИМОСТИ ОТ ЕЕ ФОРМЫ И СТАДИИ
}

\author{
*Маджидова Ё.Н., Фахаргалиева С.P. \\ Ташкентский педиатрический медииинский институт, Ташкент; \\ Ташкентская медииинская академия, Ташкент
}

В сыворотке крови 33 больных болезнью Паркинсона иммуноферментным методом изу-чен уровень нейрональной енолазы (HCE) в зависимости от формы и стадии заболевания. Наиболее высокие значения НСЕ характерны для больных до 60 лет, в большей степени для двигательной формы паркинсонизма и 2-3-й стадиями заболевания. Результаты рабо-ты доказывают обоснованность применения НСЕ в качестве дополнительного диагности-ческого маркера повреждения мозга при паркинсонизме.

Ключевые слова: паркинсонизм, нейронспецифическая енолаза, сыворотка крови.

\section{Введение}

Паркинсонизм - одно из самых распространенных органических заболеваний головного мозга, с которым постоянно встречаются практикующие неврологи [1,2,11]. Актуальность данной проблемы для медицины и здраво-охранения определяется частотой встречаемости паркинсонизма у лиц пожилого и старческого возраста, недостаточной эффективностью терапии и как следствие значительным ухудшением качества их жизни [1-3]. В основе данного неуклонно прогрессирующего нейродегенеративного заболевания лежит постепенная гибель нейронов, что проявляется мультисистемной атрофией, прогрессивным надъядерным параличем и кортико-базальной дегенерацией, вследствие накопления белка $\alpha$-амилоида $[8,10]$. Исследования ряда авторов было показано появление характерных для ткани мозга белков А $\beta-42$ амилоида, легких и тяжелых цепей нейрофиламентов, белка тау и нейрон-специфической енолазы (НСЕ) в спинномозговой жидкости и сыворотке крови больных паркинсонизмом, что позволило им говорить о неспецифических маркерах церебральной дегенерации $[5,10,11]$.

Енолаза - димерный гликолитический фермент (2-фосфо-D-глицератгидролаза), имеет 5 изоферментов ( $\alpha \alpha, \alpha \beta, \alpha \gamma, \beta \beta$ и $\gamma \gamma)$, каждая из которых имеет определенную локализацию [46]. Изоформы $\gamma \gamma$ или (НСЕ) в высоких концентрациях выявлена в нейронах и нейро-эндокринных клетках, а также в опухолях, проис- ходящих из этих клеток [5,7]. Уровень НСЕ в сыворотке низкий у здоровых людей, повышение его характерно для пациентов с нейроэндокринными опухолями. НСЕ является единственным известным в настоящее время общим маркером всех дифференцированных нейронов и относится к внутриклеточным энзимам центральной нервной системы $[5,13]$. Доказана возможность применения его для оценки степени повреждения нейронов головного мозга при ишемических и геморрагических инсультах, эпилепсии, травматической болезни головного мозга и других деструктивных заболеваний центральной нервной системы [5.13]. В литературе имеются единичные сведения о возможности его использования в качестве критерия повреждений нервной системы при паркинсонизме $[11,12]$. Однако в литературе отсутствуют сведения по изменению активности НСЕ в зависимости от формы и стадии паркинсонизма.

Цель работы - определить диагностическую значимость НСЕ у боль-ных страдающих болезнью Паркинсона (БП) в зависимости от формы и ста-дии данной патологии.

\section{Материал и методы}

Под наблюдением было 33 пациентов с паркинсонизмом, находивших-ся на амбулаторном лечении в Центральной поликлинике №2 Медико-санитарного объединения, г.Ташкента, из них 17 (51,5\%) женщин, средний возраст которых составил $(75$ 12,5) лет и $16(48,5 \%)$ мужчин, средний возраст - $(73$ 10,3) лет. Длительность заболевания - от 1 года до

*e-mail: madjidova1@yandex.ru 
14 лет. Верификация диагноза паркинсонизма осуществлялась на основании общепринятой классификации по МКБ-10 от 1995 г. (G20 - G23) с уточнением стадии болезни по Хен и Яру (1967). Всем пациентам проводилось необходимое клинико-неврологическое обследование, включающее сбор жалоб, уточнение анамнестических данных, исследование неврологического статуса.

Определялось содержание НСЕ в сыворотке крови больных методом твердофазного иммуноферментного анализа, выполняемого с помощью спе-цифических тест-систем, разработанных на основе соответствующих моно-клональных антител, на анализаторе ELISA (Швеция) с помощью Human Neuron Specific Enolase ELISA Kit (Alpha diagnostic, USA) согласно инструк-ции, прилагаемой к набору. Статистическую обработку результатов проводили с использованием параметрического t-критерия Стьюдента.

\section{Результаты и обсуждение}

Среди больных с паркинсонизмом (основная группа) у 29 (87,9\%) па-циента была диагностирована БП, из них 14 (48,3\%) женщина и $15(51,7 \%)$ мужчин, вторичный паркинсонизм (сосудистого генеза) наблюдался у 4 $(12,1 \%)$ больных, из них у $3(75 \%)$ женщин и 1 $(25 \%)$ мужчин. При проведении клинико-неврологического и анамнестического исследования основной группы выявлено, что дебют заболевания в 90,9\% случаев (30 пациента) отмечался преимущественно в 59-66 лет и лишь у $3(9,1 \%)$ - до 45-летнего возраста. По возрастному составу обследуемые больные распределились следующим образом: до 60 лет - 3 $(9,1 \%), 61-70$ лет - 4 (12,1\%), 71-80 лет - 12 (36,4\%), свыше 80 лет - 14 (42,4\%). Следовательно, наибольшее количество пациентов основной группы были в возрасте 80 лет и старше.

На момент обследования по преобладанию клинических проявлений были выделены следующие синдромы паркинсонизма: акинетико-ригидная (АРФ) - у 2 (6,1\%), ригиднодрожательная (РДФ) - у 25 (75,8\%) и дрожательная (ДФ) - у 6 (18,2\%) человек. Быстрый темп прогрессирования болезни был отмечен у $16(48,5 \%)$ больных, медленный - у 9 (23,3\%) и умеренный - у $8(24,2 \%)$ пациентов. Начальными проявлениями болезни у лиц с болезнью Паркинсона были тремор покоя в 22 случаях $(66,7 \%)$. Тремор обычно начинался с дистальных отделов рук по типу "счета монет", при этом в 54,5\% случаев - правой, в 36,4\% левой и только в 9,1\% случаях - в ногах. По мере прогрессирования заболевания присоединялся тремор в контралатеральной руке и (или) ноге, а у $5(15,1 \%)$ больных еще и присоединилось дрожание головы и нижней челюсти. У 6 (18,2\%) пациентов дебют заболевания начинался с общей скованности, у 3 (9,1\%) - с нарушения походки по типу шаркающей.

Сосудистый паркинсонизм - синдром, который может быть вызван различными цереброваскулярными заболеваниями, поражающими "страте-гические" для паркинсонизма зоны. При обследовании пациентов с сосудистым паркинсонизмом они предъявляли жалобы на практически постоянные головные боли давящего характера, шум в голове и ушах, головокружение несистемного характера, пошатывание при ходьбе, ощущение тяжести в но-гах при стоянии, частые позывы к мочеиспусканию. Эти больные наблюда-лись в течение 10-15 лет с диагнозом гипертоническая болезнь II стадии. У них отмечались повышенные цифры артериального давления до 170-200/100-120 мм рт. ст. В неврологическом статусе у этих пациентов преобладали рефлекторные расстройства в виде повышения глубоких рефлексов преимущественно нижних конечностей, появления патологических знаков. Кроме того, были выявлены вестибуло-мозжечковый и псевдобульбарный синдромы, а также выраженная ригидность, гипокинезия и нарушение ходьбы. На МРТ головного мозга были выявлены ишемические очаги в среднем мозге $(24,2 \%)$, базальных ганглиях $(48,5 \%)$, церебральная атрофия с расширением желудочковой системы и корковых борозд во всех случаях.

Анализ уровня НCE в сыворотке крови больных с паркинсонизмом показал превышение нормативных значений у 25 (75,8\%) больных. При этом колебания уровня $\mathrm{HCE}$ 
колебались в широких пределах от 21,27 нг/мл до 78,09 нг/мг, в среднем составляя $36,37 \pm 2,21$ нг/мл. Существенных различий в распределении больных по уровню НСЕ в зависимости от пола мы не выявили. Так, высокие значения фермента выявлены у 70,6 и $81,3 \%$ мужчин и женщин, причем, абсолютные их значения также не отличались, составляя $36,11 \pm 2,55$ и $36,60 \pm 3,55$ нг/мл у пациентов с высоким уровнем НСЕ, соответственно полу. Анализ уровня НСЕ в зависимости от возраста больных показал, что высокие значения данного фермента характерны для всех боль-

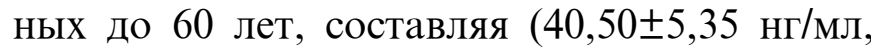
$\mathrm{P}<0,01)$. В других возрастных группах больных с высоким уровнем НСЕ не превышает $50-83,3 \%$, а диапазон абсолютных значений от $27,96 \pm 3,01$ нг/Мл до $38,36 \pm 4,31$ нг/мЛ.
Представляло интерес сопоставление значений НСЕ от формы паркинсонизма (табл.). Проведенный анализ показал, что у больных с ДФ паркинсонизма средние значения уровня НСЕ составили $38,13 \pm 2,99$ нг/мл, причем высокие значения были отмечены у всех 6 больных. В то же время у пациентов с ДРФ болезни, хотя абсолютные значения данного фермента существенно не отличались от группы с ДФ, однако высокие его значения были выявлены у 69,2\% больных, а низкие - у $30,8 \%$ пациентов, средние значения составили $41,67 \pm 3,03$. При этом абсолютные значения HCE у пациентов с высоким уровнем несколько превышал показатели больных с ДФ заболевания. Следовательно, ДРФ паркинсонизма характеризуется более высокими значениями титра антител к НСЕ.

\section{Уровень НСЕ у больных с болезнью Паркинсона в зависимости от формы и стадии заболевания, $\mathrm{M} \pm m$}

\begin{tabular}{|l|l|l|l|}
\hline \multirow{2}{*}{ Формы и стадии } & Уровень НСЕ, нг/мл & больше 25 нг/мл & меньше 25 нг/мл \\
\cline { 2 - 4 } & общее & $38,13 \pm 2,99$ & $0,0 \pm 0,0$ \\
\hline Формы паркинсонизм: & $38,13 \pm 2,99$ & $41,67 \pm 3,03$ & $23,85 \pm 0,37$ \\
\hline ДФ & $37,88 \pm 2,71$ & $40,99 \pm 2,47$ & $0,0 \pm 0,0$ \\
\hline ДРФ & $40,99 \pm 2,47$ & $44,19 \pm 5,20$ & $22,79 \pm 0,55$ \\
\hline Стадии паркинсонизма: & $38,07 \pm 5,21$ & $40,20 \pm 5,37$ & $22,51 \pm 0,35$ \\
\hline 2 & $33,39 \pm 4,08$ & $32,40 \pm 2,29$ & $24,73 \pm 0,38$ \\
\hline 3 & $29,84 \pm 2,80$ & & \\
\hline 5 &
\end{tabular}

Анализ уровня НСЕ в зависимости от стадии заболевания показал вы-сокие ее значения у пациентов со 2-й стадией, составляя

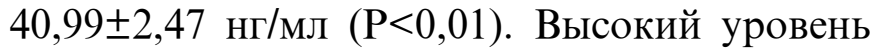
данного фермента был установлен у всех обсле-дованных больных со 2-й стадией паркинсонизма. По мере прогрессирования патологического процесса значения титров НСЕ постепенно снижались, видимо, связанное постепенным уменьшением числа функционально активных нейронов и, возможно, с накоплением амилоидных белков. Следует отметить, что больных с 3-й стадией болезни Паркинсона уровень НСЕ был несколько ниже значений предыдущей группы больных. Однако анализ уровня его в зависимости от вы- сокого и низкого уровня показал, что у 5 из 7 больных $(71,4 \%)$ отмечен высокий уровень HCE, превышающий даже значения больных co 2-й стадией паркинсонизма. У 61,5\% больных с 4-й стадией паркинсонизма сохранялся существенно высокий уровень НСЕ. Эти значения были несколько ниже показателей группы пациентов с 3-й стадией и существенно не отличались от группы больных со 2-й степенью патологии. Однако, абсолютные значения НСЕ у больных с 5-й стадией БП были достоверно ниже показателей больных co 2-й и 3-й степенью заболевания. В этой группе больных частота высоких значений НСЕ составила 66,7\%, а их абсолютные значения достоверно отличались от норматив- 
ных, но все же были статистически значимо ниже значений пациентов со 2-й и 3-й стадиями тяжести.

Анализ уровня НCE в зависимости от темпа прогрессирования заболе-вания показал, что чаще высокие значения фермента были характерны для больных с быстрым темпом прогрессирования $(61,1 ; 55,6$ и $37,5 \%$, соответственно быстрым, умеренным и медленным типами прогрессирования), абсолютные значения фермента у этих больных были существенно выше.

Согласно данным литературы [4-6], при заболеваниях, сопряженных с непосредственным вовлечением в патологический процесс нервной ткани, качественные и количественные определения этого белка в сыворотке крови дают ценную информацию о степени выраженности повреждений нейронов и нарушениях общей целостности гематоэнцефалического барьера. В то же время, по мнению других, высокие значения НСЕ в большей степени харак-терны при распространении патологического процесса на оболочки мозга [7].

По мнению И.С. Преображенской и соавт. (2001), высокие значения нейрон-специфических белков у больных с БП отмечаются уже с ранний ста-дий заболевания и характерны

\section{ЛИТЕРАТУРА}

1. Багыева Г.Х. /Клинико-генетический и биохимический анализ болезни Паркинсо-на: Механизмы предрасположенности, экспериментальные модели, подходы к терапии //Автореф. дисс... д.м.н.- М., 2009.- 48c.

2. Иллариошкин С.Н. Молекулярные основы болезни Паркинсона //Сборник I Национального конгресса по болезни Паркинсона и расстройствам движений.- М., 2008.- C. 8-17.

3. Левин О.С. Клиническая эпидемиология болезни Паркинсона //В кн. Болезнь Пар-кинсона и расстройства движений: Руководство для врачей по материалам II На-ционального конгресса.- М., 2011.- С.5-9.

4. Морозов Г.В., Морковкин В.М., Коротеева Е.А. и др. Иммуноферментный анализ глиоспецифических антигенов и аутоантител к ним в сыворотке крови больных с критическими состояниями, обусловленными психическими заболеваниями (Неотложные состояния в психиатрии) //Нейро-психиатр. журн.- 1998.- №3.- С.115-121.

5. Преображенская И.С., Чехонин В.П., Яхно Н.Н. Проницаемость гематоэнцефали-тического барьера при болезни Альцгеймера и паркинсонизме с когнитивными на-рушениями //Журн. неврологии и психиа- для пациентов с деменцией [5]. Экспериментальными исследованиями на мышах с хронической моделью паркинсонизма была показана экспрессия белков HCE, S100B и GFAP в ткане мозга, наибольшие изменения были характерны для НСЕ [9]. На наш взгляд, у больных БП прогрессирующее повреждение нейронов начинается на ранних стадиях, что проявляется наличием локальных воспалительных явлений, обусловливая вымывание НCЕ в биологические жидкости. Стихание этих процессов на более поздних стадиях с отложением амилоидных белков уменьшает их поступление в жидкости. На основании полученных данных можно предположить, что определение сывороточной НСЕ может свидетельствовать о развитии патологии в нейронах в ранние сроки. На основании полученных данных можно сделать следующие выводы:

1. Анализ сывороточной НСЕ у больных с паркинсонизмом является информативным диагностическим критерием оценки нейронального повреждения головного мозга.

2. Наиболее высокие значения НСЕ характерны для больных до 60 лет, в большей степени для дрожательно -ригидной формы паркинсонизма и 2-3-й стадиями заболевания.

трии им С.С. Корсакова.- 2001.- Т.101, №5.- С.39-42. 6. Рахимбаева Г.С., Рашидова Н.С. Нейрон-специфическая енолаза в сыворотке крови как диагностический маркер эпилепсии. //

7. Чехонин В.П., Гурина О.И., Рябухин И.А. и др. Иммуноферментный анализ ней-ронспецифической енолазы на основе моноклональных антител в оценке проницаемости гематоэнцефалического барьера при нервно - психических заболеваниях //Росс. психиатр. журн.2000.- №4.- C.15-19.

8. Яхно Н.Н. Болезнь Паркинсона - достижения и новые вопросы //Сборник I Нацио-нального конгресса по болезни Паркинсона и расстройствам движений Москва, 2008.- С.7-8.

9. Al-Jarraf M.D., Jamous M. Effect of endurance exercise training on The expression of GFAP, S100B and NSE in the striatum of chroniclprogressive mouse model of Parkinson`s disease. //NeuroRehabilitation.- 2011.Vol.28(4).- P.359-363.

10. Constantinescu R., Zetterberg H., Holmberg B., Rosengren L. Levels of brain related pro-teins in cerebrospinal fluids: an aid in the differential diagnosis of 
parkinsonian disorders. //Parkinsonism Relat Disord.2009.- Vol.15(3).- P.205-212.

11. Sanyal J, Chakraborty DP, Sarkar B, Banerjee TK. et al. Environmental and familial risk factors of Parkinsons disease: case-control study. //Can J Neurol Sci.- 2010.Vol.37(5).- P.637-642.
12. Schaf D.V., Tort A.B., Frrike D. et al. S100B and NSE serum levels in patients with Par-kinson`s disease. //Parkinsonism Relat Disord.- 2005.- Vol.11(1).- P.39-43. 13. Van de Warrenburg B.P., Church A.J., Martino D et al. Antineuronal antibodies in Par-kinson`s disease. //Mov. Disord.- 2008.- Vol.23(7).- P.958-963.

\title{
XÜLASə
}

\section{PARKINSON XəSTOLIYININ FORMASINDAN VO MORHOLOSINDON ASILI OLARAQ QAN ZORDABINDA NEYRON-SPESIFIK ENOLAZANIN DӘYIŞMӘSININ XÜSUSIYYYəTLӘRI}

\author{
Məcidova E.N., Faxarqaliyeva S.R. \\ Daşkənd pediatrik tibb institutu, Daşkənd; \\ Daşkənd Tibb Akademiyası, Daşkənd
}

Parkinson xəstəliyi ilə 33 xəstənin qan zərdabında immunoferment metodu ilə neyronal enolazanın (NES) səviyyəsi, xəstəliyin formasından və mərhələsindən asılı olaraq öyrənilmişdir. NSE-nin ən yüksək qiymətləri 60 yaşdan yuxarı xəstələr, əsas etibarilə parkinsonizmin hərəki forması və 2-3-cü mərhələsi üçün xarakter olmuşdur. Tədqiqat işinin nəticələri parkinsonizm zamanı NSE-nin beyinin zədələnməsinin əlavə diaqnostik markeri qismində istifadəsinin əsaslı olmasını sübut edir.

Açar sözlər: parkinson xəstəliyi, neyron-spesifik enolaza, qan zərdabı.

\section{SUMMARY}

\section{PROPERTIES OF CHANGES NEURON-SPECIFIC ENOLASE IN BLOOD SERUM OF PATIENTS WITH PARKINSON'S DISEASE DEPENDING ON THE FORM AND STAGE}

\author{
Madjidova E.N., Fahargaliyeva S.R. \\ Tashkent Medical Pediatric Institute, Tashkent \\ Tashkent Medical Academy, Tashkent
}

In the serum of 33 patients with Parkinson's disease studied by ELISA level of neuronal enolase (NSE), depending on the form and stage of the disease. The highest levels of NSE are character-istic for patients up to 60 years, to a greater extent for the motor forms of Parkinsonism and 2-3rd stages of the disease. The results prove the validity of NSE as an additional of diagnostic marker of brain damage in Parkinsonism.

Key words: Parkinson's disease, neuron-specific enolase, blood serum. 